\title{
High Range Turbidity Monitoring in the Mu and Saru River Basins: All-year Monitoring of Hydrology and Suspended Sediment Transport in 2010
}

\author{
Takaaki ABE ${ }^{1}$, Shigeru MIZUGAKI ${ }^{1}$, Toshihito TOYABE $^{2}$, Masahiro MARUYAMA ${ }^{1}$, \\ Yasuhiro MURAKAMI ${ }^{1}$ and Takashi ISHIYA ${ }^{2}$ \\ ${ }^{1}$ Civil Engineering Research Institute for Cold Region, Sapporo, Japan \\ (Hiragishi, Toyohira-ku, Sapporo City, Hokkaido 0628602, Japan) \\ E-mail: abe-t@ ceri.go.jp \\ ${ }^{2}$ Hokkaido Regional Development Bureau, Japan (Kita 8-jo, Kita-ku, Sapporo City, Hokkaido 0608511, Japan)
}

\begin{abstract}
In the processes of designing reservoirs, planning river channels and managing downstream river environments, it is very important to clarify the mechanism of transport for suspended sediment in basins and to quantitatively evaluate the amount of sediment discharge. In this study, year-round monitoring and calibration were conducted using high-range turbidimeters at five observation points in the Mu and Saru river basins, and a practical estimation equation for the evaluation of suspended sediment (SS) concentration $(\mathrm{mg} / \mathrm{L})$ as determined from the measured turbidity value $(\mathrm{ppm})$ at each point was proposed. The estimation equation is expressed as a simple linear function of discharge $Q$, and is able to accurately reproduce water sampling results and the turbidimeter measurements taken at the observation points. The characteristics of sediment discharge in the $\mathrm{Mu}$ and Saru river basins were also examined based on SS concentration values obtained from the year-round monitoring in 2010 using the simple estimation equation proposed. The study results revealed that the sediment discharge process and amount varied among the measurement points in the two basins, and that there were clear seasonal variations among the snowmelt, summer and other seasons in both basins.
\end{abstract}

Key words: high-range turbidimeter, $S S C-Q$ hysteresis, sediment transport, seasonal change

\section{INTRODUCTION}

Recently, the importance of consistent sediment management throughout river basins has been recognized. Sediment produced in mountain areas causes a variety of problems in basins, such as a reduction of reservoir capacity, adverse effects on the ecosystem, and coastline setback. Many such problems are attributable to suspended sediment flowing down through basins. In this regard, it is important to gain a proper understanding of the actual state of suspended sediment production and transport.

In previous research on suspended sediment transport in basins, sediment discharge caused by large-scale surface erosion of cultivated land in a large basin was studied [Wass et al., 1999], the impacts of forest management on suspended sediment discharge and surrounding riparian ecosystems in a humid tropical region were assessed
[Chappell et al., 2004], and the characteristics of sediment discharge in alpine watersheds were investigated [Mano et al., 2009].

Such studies have also been conducted in relation to rivers in Japan. By way of example, Ahn et al. [2008] assessed the environmental load of suspended sediment and nutrients discharged from farmland in a basin. Another study [Yoshikawa et al., 2005] assessed changes in material transport before and after large-scale flooding in the Saru River (where this study was also conducted), and further work [Fujita et al., 2003] clarified sediment dynamics with a focus on the sediment production process in a river source region.

In order to appropriately assess the amount of suspended sediment being transported (as did these previous studies), it is important to monitor sediment concentration continuously [Bisantino, 2011]. Among a number of methods for quantitatively monitoring suspended sediment transport, turbidimeters are becoming popular as 


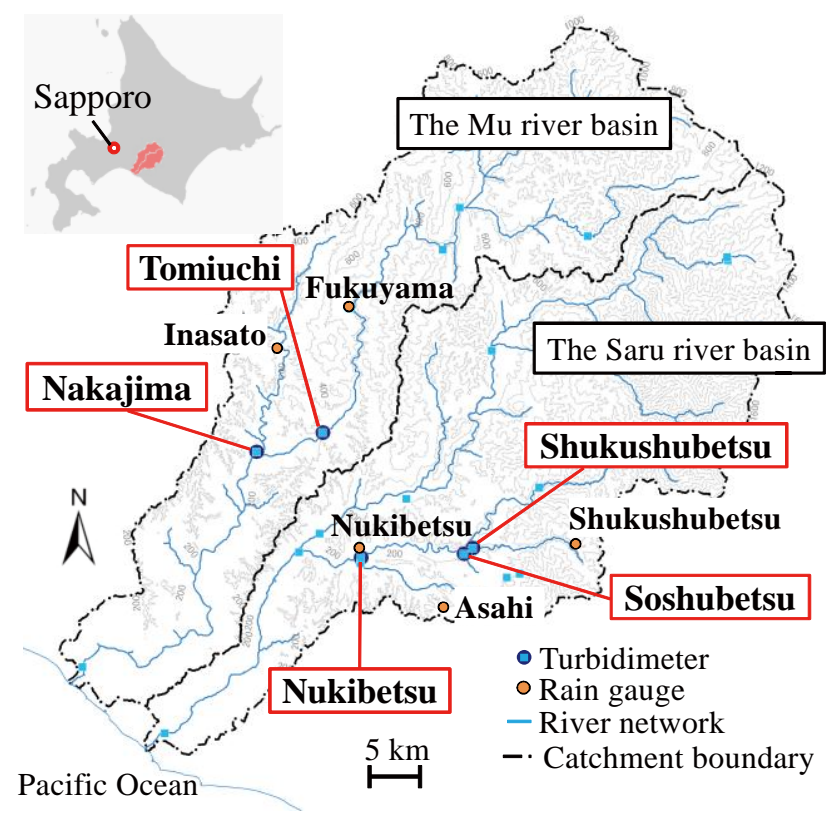

Fig.1 Location Maps of the studied subcatchment.

instruments for the observation of sediment dynamics because their installation in river channels enables continuous monitoring for long periods of time [Yokoyama, 2002].

Lewis [1996] and many others have attempted to clarify SS concentration based on measurements taken with turbidimeters, with which concentrations of $2,000 \mathrm{mg} / \mathrm{L}$ or less were measured. The concentration range that can be measured with ordinary turbidimeters is up to $1,000-2,000 \mathrm{mg} / \mathrm{L}$. In this measurement range, the relationship between turbidity and SS concentration was almost linear. However, according to Yokoyama, 2002, Yokoyama et al., 2008 and Yokoyama et al., 2010, a linear relationship with SS concentration is not maintained in high-turbidity conditions, with concentration values under the same turbidity level varying fourfold or more. Accordingly, the use of the $L-Q$ equation, which assumes a $1: 1$ relationship between discharge and SS concentration, may result in large errors.

Few studies have assessed suspended sediment dynamics in high-turbidity regions because of the limit of turbidity sensor and estimation method for SS concentration. For better watershed sediment management in such high-turbidity regions, the characteristics of suspended sediment transport should be clarified based on an appropriate observation and assessment of SS concentration. The objectives of this study are to develop a practical method of SS concentration estimation for high-turbidity region and to clarify the characteristics of suspended sediment transport in catchment scale. In order to attain our goals, we performed calibration of the high-range turbidimeter we used and carried out an all-year monitoring of suspended sediment transport in the target basins.

\section{STUDY METHOD}

\subsection{Target basins}

As shown in Fig. 1, the areas surveyed in the study were the $\mathrm{Mu}$ and Saru river basins located on the Pacific coast of Hokkaido. The areas and other characteristic values of each subcatchment region are listed in Table 1. It is known that suspended sediment is naturally released in these basins because of the geological conditions of their upper reaches. It has been reported that $80 \%$ of sediment produced from shallow landslides that occurred in areas of dense soil during heavy rains in August 2003 still remains in the basins and is gradually being transported to the lower reaches [Murakami et al., 2008], causing reservoir sedimentation and other serious problems.

\subsection{Field observation}

In this study, hydrological and sediment transport data were observed at five subcatchment areas in Soshubetsu and Shukushubetsu (small catchments) and in Nakajima, Tomiuchi and Nukibetsu (medium-sized catchments). Monitoring was conducted every 10 minutes throughout 2010. For rainfall gauging, data from rain gauge stations as shown in Table $\mathbf{1}$ were used. Water levels were continuously monitored at the five observation points, and changes in discharge over time were determined based on the Stage-Discharge curve found from the water level monitored at each observation point in advance.

Turbidity (ppm) was measured every 10 minutes using high-range turbidimeters, i.e. ATU3-8M with a measurement range of $0 \mathrm{ppm}$ to $20,000 \mathrm{ppm}$ and

Table 1 Main characteristics of the 5 subcatchments studied

\begin{tabular}{|c|c|c|c|c|c|}
\hline Subcatchment & Nakajima & Tomiuchi & Nukibetsu & Soshubetsu & Shukushubetsu \\
\hline Area $\left[\mathrm{m}^{2}\right]$ & 200 & 723 & 290 & 17 & 64 \\
\hline Rain Gauge Station & Inasato & Fukuy ama & Toyonuka & Asahi & Shukushubetsu \\
\hline Annual Precipitation 2010 [mm] & 1418 & 1521 & 1286 & 1668 & 1728 \\
\hline Turbidimeter & ATU75W-USB & ATU3-8M & ATU75W-USB & ATU75W-USB & ATU75W-USB \\
\hline
\end{tabular}



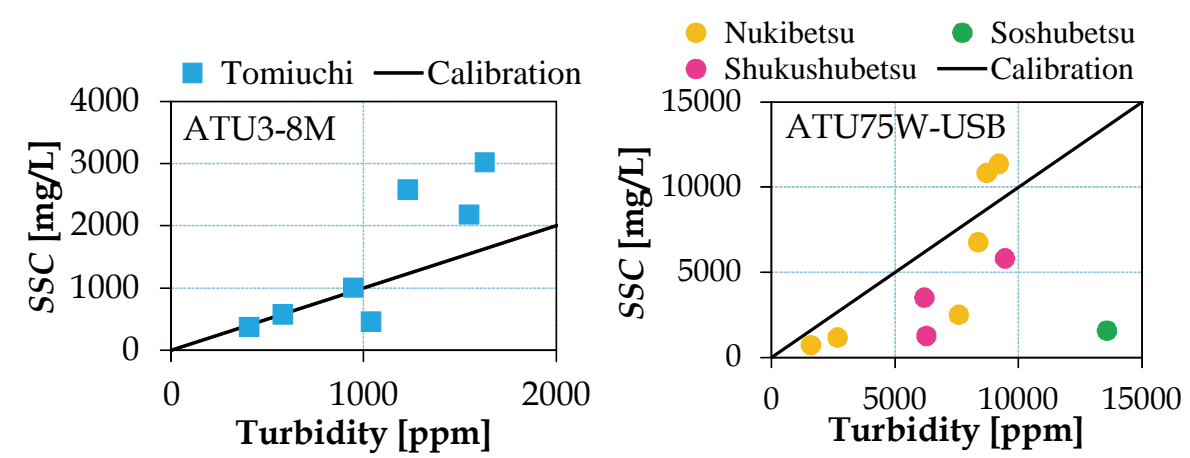

Fig. 2 Relationship between Turbidity (ppm) and SSC (mg/L) measured at Tomiuchi by ATU3-8M and at Nukibetsu, Soshubetsu and Shukushubetsu by ATU75W-USB

ATU75W-USB with 0 ppm to 100,000 ppm (JFE Advantech, Japan). Manufacturers' test was conducted to calibrate both turbidimeters using kaolin clay with a mean diameter of $0.6 \mu \mathrm{m}$.

To calibrate measured turbidity and SS concentration values, surface water was sampled during four floods in the snowmelt season and one flood in the summer season at the points where the turbidimeters were installed. After water samples containing suspended sediment collected at each point had been allowed to settle, the clean water was removed and the remaining sediment was dried for use as analytical samples. In this study, the term SS concentration refers to the concentration of total suspended matter, including minerals and organic content. SS concentration $(\mathrm{mg} / \mathrm{L})$ was calculated using relationships among Turbidity, Discharge and SS concentration discussed in Section 3.2.

\subsection{Analytical method}

The method for analyzing and processing observation data is described here. Raw data from turbidimeters fluctuate greatly, especially during periods of flooding. Data were rejected in cases where turbidimeters were considered to be above the water surface or buried in sediment judging from water level data in relation to the elevations of turbidimeter installation locations. For the remaining measurements, spike data and abnormal data collected during winter that probably related to frozen river conditions were rejected, and movements within 30 minutes before and after a certain point in time were averaged to obtain hourly data.

Flood events with a total amount of rainfall exceeding $20 \mathrm{~mm}$ were extracted from the whole data set. Then, SS concentration-Discharge graphs were plotted on logarithmic axes to classify suspended sediment discharge patterns for the floods examined. For each flood event, hysteresis patterns of SS concentration-Discharge were summarized and simply divided into the three categories of Clockwise (CW), Counter-Clockwise (CCW) and Simultaneous Peaks (SP) according to the concept proposed by Williams [1989]. Of the events classified into $\mathrm{CW}$ and $\mathrm{CCW}$, those showing figure-of-eight loops were extracted.

Suspended sediment load (SSL, ton) exported during a single event was estimated using the following equation:

$$
S S L=3.6 \cdot \sum_{i=1}^{n}(Q \cdot S S C),
$$

where $n$ corresponding to the number of 1-hour intervals during the event of interest. By calculating the ratio between the SS load and the runoff volume for each event, a mean SS concentration value (Mean $S S C, \mathrm{mg} / \mathrm{L}$ ) per event was obtained as follows:

$$
\text { Mean } S S C=S S L /\left(3.6 \cdot \sum_{i=1}^{n} Q\right) .
$$

\section{SUSPENDED SEDIMENT MONITORING RECORDS TAKEN USING TURBIDIMETERS}

\subsection{Suspended sediment monitoring records}

The first step for the calculation of SS concentration from records monitored with turbidimeters is to calibrate turbidity. In this study, SS concentration determined by sampling surface water was compared with the turbidity level recorded at each sampling time. The measurements taken with the turbidimeters were correlated with SS concentration values determined by surface water sampling during floods and plotted separately for the $\mathrm{Mu}$ and Saru river basins, as shown in Fig. 2.

Turbidimeter calibration was conducted to the manufacturer's specifications using kaolin clay. The solid lines shown in the figures are calibration lines for kaolin clay. If particles flowing down the river channels had the same properties, size and distribution as those of the kaolin clay used in the calibration, their values will be plotted on the calibration line. 


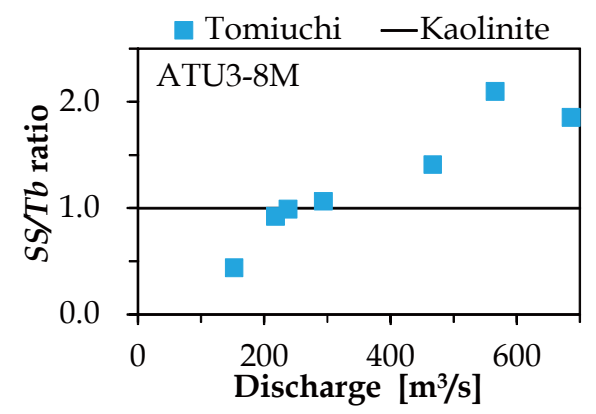

(a) ATU3-8M

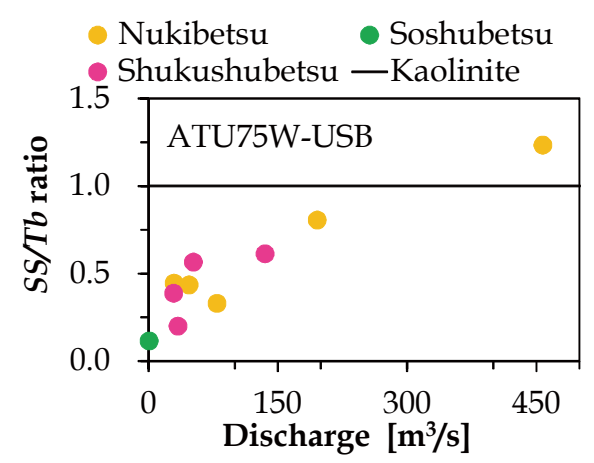

(b) ATU75W-USB

Fig.3 Turbidimeter-specific relationships between stream discharge and $S S / T b$ ratio

However, as shown in the figures, not all the SS concentration values obtained from these observation points are plotted on the calibration line. The Tomiuchi data for approximately $1,000 \mathrm{ppm}$ or less are plotted on the line, meaning that the optical properties of suspended sediment transported under this condition were similar to those of the kaolin used in the calibration, whereas those for $1,200 \mathrm{ppm}$ or more deviate greatly from the line. In the range where data are plotted above the line, the ppm value is underestimated.

In contrast, turbidity was overestimated at Soshubetsu and Shukushubetsu. At Nukibetsu, it tended to be overestimated when the ppm value was low and underestimated when the value increased to approximately $8,000 \mathrm{ppm}$ or more. According to Yokoyama [2002], the maximum diameter of particles measurable with a turbidimeter is as small as $0.42 \mathrm{~mm}$ (fine sand or smaller in soil classification). However, a monotonically increasing relationship is clearly seen between turbidity (ppm) and SS concentration $(\mathrm{mg} / \mathrm{L})$.

Sumi et al. [2006] selected the SS/Tb ratio as an indicator to examine the causes of fluctuations in suspended sediment $(S S)$ and turbidity $(T b)$, and concluded that the variations stemmed from changes in the distribution of particle size in the sediment being transported. In accordance with this approach, the present study was conducted based on changes in the $S S / T b$ ratio.

\subsection{Turbidity correction formula for SS concentration assessment}

Assessment of the amount of suspended sediment based on turbidity $T b$ (ppm) requires an equation to enable estimation of SS concentration. The aforementioned fluctuations in concentration and turbidity are probably caused by changes in the size composition of the particles being transported [Yokoyama, 2002: Yokoyama et al. 2008]. The extent to which changes in the color and lithological characteristics of sediment transported during floods affect turbidity measurements was considered small [Yokoyama, 2002].

The distribution of sediment particle sizes in flowing water is defined by the hydraulic quantity in a river channel, and suspended sediment in particular is considered to be transported mainly by the velocity field near its particles. As the water level was continuously measured at the observation points, it is easier to use discharge $Q$ (which can be assessed simply based on stage-discharge curves) as an indicator of the velocity field. For this reason, SS is estimated using $Q$ as an indicator of changes in the distribution of particle size in sediment transported and turbidity $T b$. As both $S S$ and $T b$ are functions of particle size, i.e., discharge, the following equation can be assumed:

$$
S S / T b=f(Q) .
$$

$f(Q)$ should be found in a form suitable for practical use. $S S / T b$ ratios plotted based on surface water sampling results and turbidimeter measurements revealed that $S S / T b$ increased monotonically with $Q$ for each turbidimeter, exhibiting an almost linear relationship as shown in Figs. 3 (a) and (b). Linear regression resulted in the following equations.

$$
\begin{gathered}
f(Q)=0.0027 Q+0.2482 \\
\left(R^{2}=0.877 ; \text { for ATU3-8M }\right) \\
f(Q)=0.0020 Q+0.2898 \\
\left(R^{2}=0.904 ; \text { for ATU75W-USB }\right)
\end{gathered}
$$

For the discussion of SS concentration in this study, $S S(\mathrm{mg} / \mathrm{L})$ was calculated based on the equation $S S$ $=f(Q) \times T b$.

\subsection{Effects of channel sediment transport capacity on turbidity measurements}

This section discusses the correlation shown in the previous section. From a hydraulic viewpoint, the amount of sediment that can be transported in a river channel is thought to be controlled by hydraulic parameters such as cross-section mean velocity $\bar{U}$, particle setting velocity $w_{s}$ and the vertical component of turbulent velocity [Dietrich, 1982]. The relationship between $\bar{U}$ and tractive 
Table 2 Hysteresis direction ${ }^{* 1}$ for flood events at 5 points in the Mu and Saru River. Dashes (-) represent missing data.

\begin{tabular}{|c|c|c|c|c|c|}
\hline $\begin{array}{l}\text { Site \& Area } \\
\text { Event date }\end{array}$ & $\begin{array}{l}\text { Nakajima } \\
200\left[\mathrm{~km}^{2}\right]\end{array}$ & $\begin{array}{l}\text { Tomiuchi } \\
723\left[\mathrm{~km}^{2}\right]\end{array}$ & $\begin{array}{c}\text { Nukibetsu } \\
290\left[\mathrm{~km}^{2}\right]\end{array}$ & $\begin{array}{c}\text { Soshubetsu } \\
17\left[\mathrm{~km}^{2}\right]\end{array}$ & $\begin{array}{c}\text { Shukushubetsu } \\
64\left[\mathrm{~km}^{2}\right]\end{array}$ \\
\hline 21-23 Mar & - & $\mathrm{CCW}$ & $\mathrm{CCW}$ & & $\mathrm{CW}(8)$ \\
\hline 1-6 Apr & - & $\mathrm{CCW}$ & CCW (8) & - & CW \\
\hline 6-10 Apr & - & SP & - & - & $\mathrm{CW}$ \\
\hline 10-13 Apr & - & SP & - & - & $\mathrm{CW}$ \\
\hline 13-16 Apr & - & SP & $\mathrm{CW}$ & - & CW (8) \\
\hline 21-22 Apr & - & - & - & $\mathrm{CW}$ & - \\
\hline 29 Apr - 2 May & - & $\mathrm{CW}$ & - & - & - \\
\hline 2-6 May & - & $\mathrm{CCW}$ & - & - & - \\
\hline 6-9 Мау & - & - & $\mathrm{CW}$ & - & - \\
\hline 16-17 Jun & - & SP & SP & $\mathrm{CW}$ & - \\
\hline 23-24 Jun & - & - & - & $\mathrm{CW}$ & - \\
\hline $1-2 \mathrm{Jul}$ & - & - & - & $\mathrm{CW}$ & - \\
\hline $3 \mathrm{Jul}$ & - & - & $\mathrm{CCW}$ & $\mathrm{CW}$ & - \\
\hline 4-5 Jul & - & - & $\mathrm{CCW}$ & - & - \\
\hline 12-14 Jul & - & $\mathrm{CW}(8)$ & $\mathrm{CCW}$ & - & - \\
\hline 22-23 Jul & - & - & - & $\mathrm{CCW}$ & - \\
\hline 27-29 Jul & - & - & $\mathrm{CW}$ & - & - \\
\hline $29 \mathrm{Jul}-1$ Aug & - & - & CW & - & - \\
\hline 1-4 Aug & - & - & $\mathrm{CCW}$ & - & - \\
\hline 8-9 Aug & - & - & $\mathrm{SP}$ & - & - \\
\hline 11-15 Aug & - & $\mathrm{CW}$ & $\mathrm{CCW}$ & - & - \\
\hline 15-16 Aug & - & $\mathrm{CCW}$ & CW & - & - \\
\hline 23-27 Aug & - & CCW & - & - & - \\
\hline 24-26 Aug & - & - & SP & - & - \\
\hline 6-9 Sep & - & $\mathrm{CCW}$ & - & - & - \\
\hline 18-19 Sep & - & - & - & CCW $(8)$ & $\mathrm{CCW}$ \\
\hline 28-29 Sep & $\mathrm{CCW}$ & SP & - & $\mathrm{CCW}(8)$ & $\mathrm{CCW}$ \\
\hline $4-6$ Oct & CW & CW & CW & $\mathrm{CCW}$ & - \\
\hline 10-11 Oct & CW & CW & - & - & - \\
\hline 15-18 Oct & SP & CCW (8) & - & - & - \\
\hline 9-13 Nov & CW & CW & - & SP & CCW \\
\hline 22-23 Nov & - & - & - & SP & $\mathrm{CCW}$ \\
\hline 3-6 Dec & $\mathrm{CCW}$ & SP & - & SP & $\mathrm{CCW}$ \\
\hline
\end{tabular}

${ }^{* 1} \mathrm{CW}=$ Clockwise; $\mathrm{CCW}=$ Counter-clockwise hysteresis and $\mathrm{SP}=$ Simultaneous Peak

force $\tau_{0}$ can be expressed as $\tau_{0}=\rho g \bar{U}^{2} / C^{2}$ (where $C$ is the Chezy coefficient) and setting velocity $w_{s}$ can be expressed as $w_{s} \propto D^{2}$ provided that particles are spherical based on Stokes' law. Thus, it is understood that if the hydraulic quantity in a river changes, the particle size of sediment being transported also changes.

According to Mie scattering theory, the scattering intensity $(=$ turbidity $)$ of particles measuring $1 \mu \mathrm{m}$ or more in size is proportional to the concentration and particle surface area in measurements taken with an infrared turbidimeter. The following equation is given for single particle size [Yokoyama, 2002]:

$$
T b=\alpha\left(\frac{1}{d}\right)^{n} S S \Rightarrow S S / T b=\alpha^{-1} d^{n}
$$

Here, $\alpha$ and $n(>0)$ are correction factors. In this case, it is apparent that $S S / T b$ will increase when discharge increases, and as a consequence, the value of $d$ for transported sediment becomes large. In cases of sediment characterized by various particle sizes, an increase in discharge will result in particle size distribution shifting to a larger mean particle size $d_{m}$. As it is considered that any given value of $d_{m}$ satisfies this equation, even $S S / T b$ values with a wide particle size distribution are expected to increase with greater discharge.

For turbidity calibration in this study, SS concentration was calculated based on surface water sampling during periods of flooding. However, velocity distribution is generally seen in the direction of water depth [Yokoyama et al., 2000], and the size distribution of suspended sediment particles near the water surface may differ from that seen at the levels of turbidimeter installation. Accordingly, further study is needed in this area. With respect to the vertical distribution of SS concentration, Toyabe et al. [1998] conducted field measurements in river basins and reported no large variations. This study therefore assumed that the vertical distribution of SS concentration had little effect on measured turbidity values.

\section{SEASONAL CHANGES IN SEDIMENT DISCHARGE}

\subsection{SS concentration- $Q$ hysteresis patterns}

Based on the year-round observation conducted in this study, seasonal changes in the characteristics of sediment discharge at each basin are discussed here. Table 2 lists all flood events along with their 


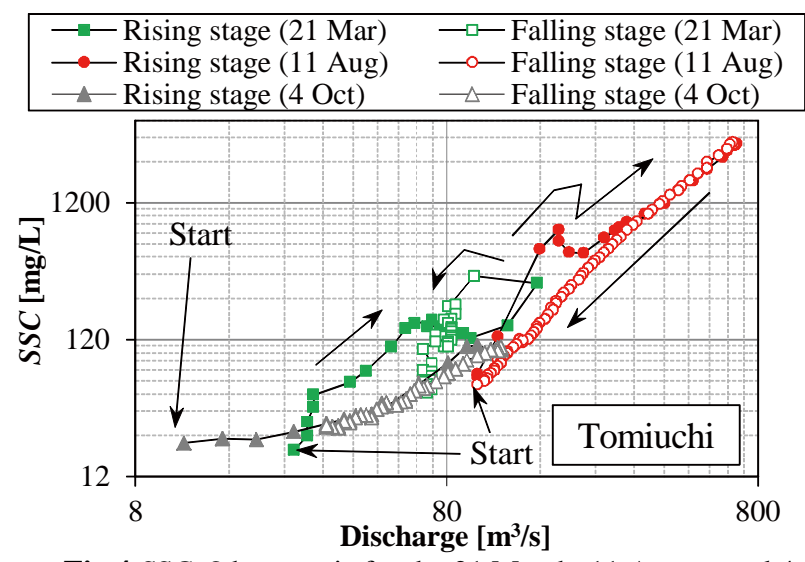

Fig.4 SSC- $Q$ hysteresis for the 21 March, 11 August and 4 October flood event (Tomiuchi).

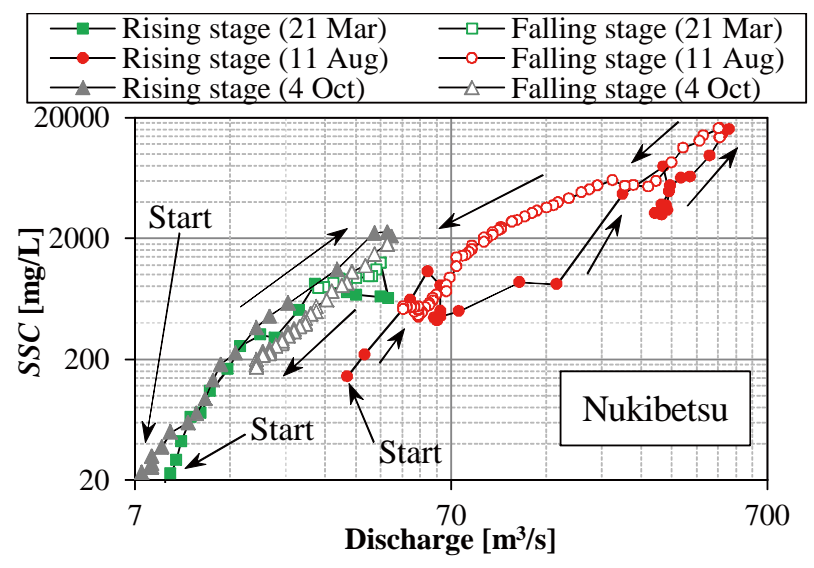

Fig.5 SSC- $Q$ hysteresis for the 21 March, 11 August and 4 October flood event (Nukibetsu).

event dates and the hysteresis patterns seen at each observation point.

In Nakajima, Tomiuchi and Nukibetsu, where the basin area was large, a variety of hysteresis patterns were observed. It appears that various suspended sediment transport processes have complex effects. For example, suspended sediment transport may be slower than flood wave propagation traveling through the long river channel, and there may be differences in rainfall distribution as well as in the erodibility of sediment distributed in the basins. These effects are probably strong in large basin areas, while rainfall distribution changes over time, and sediment deposition conditions may be altered by previous rainfall events. Thus, it can be said that large basin areas are characterized by a variety of factors that affect hysteresis patterns, making it difficult to identify these patterns.

In contrast, hysteresis at Soshubetsu and Shukushubetsu, where the basin area was relatively small, showed an apparent seasonal trend. Only the $\mathrm{CW}$ type was seen in summer before the rainy season, and after that the CCW hysteresis type was generally observed. The SP type was mainly observed after November only at Soshubetsu. CW loops were observed at least between late April and early July at Soshubetsu and between March and mid-April at Shukushubetsu, although the table shows no cases of CW loops observed simultaneously at Soshubetsu and Shukushubetsu due to missing data. Such clockwise hysteresis reportedly results from the effects of stirred-up riverbed sediment [Kurashige, 1996]. Accordingly, it can be inferred that suspended sediment in these small basins during the snowmelt season mostly came from riverbed matter.

However, hysteresis at these two basins after summer was limited to the CCW and SP types. Kurashige [1996] concluded in his study conducted in another basin that hysteresis patterns were affected by sediment supplied from slopes, and similar sediment supply probably also occurred in the target basins of this study. It is notable that the hysteresis trend changed after summer. Soil banks that collapsed near the rivers during the rainy season in these two basins seem to have made an ongoing contribution to suspended sediment discharge until winter.

\subsection{Comparison of events in the snowmelt, summer and autumn seasons at Tomiuchi and Nukibetsu}

To support detailed discussion of the sediment discharge characteristics observed in each basin, this section presents the hysteresis patterns seen during floods that occurred on 21 March in the snowmelt season, on 11 August in summer and on 4 October in autumn at Tomiuchi and Nukibetsu (Figs. 4 and 5). It can be seen from Fig. 4 that hysteresis patterns differed among the events in the three months. Comparison of the March and October events reveals that they were similar in terms of discharge scale, although there were several-fold differences in SS concentration over a relatively long period of time.

The flood event in August had high discharge, and high SS concentration values were plotted. In the March and August events, SS concentration increased, decreased, increased again, and then the peak discharge was reached. The first peak can be explained by riverbed sediment beginning to move again [Kurashige, 1985; Kurashige, 1994], and the subsequent peak is considered to be caused by sediment that was not supplied to the channels earlier, such as that from collapsed slopes and stirred-up suspended sediment from flood channels. The white marks plotted for the last half of the August and October flood events form separate curves, confirming that there was a relationship of 


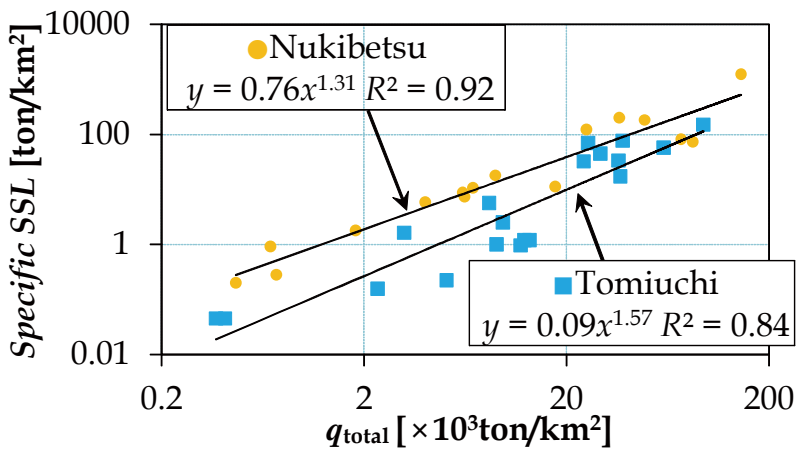

Fig.6 Relations between Specific $S S L\left[\mathrm{t} / \mathrm{km}^{2}\right]$ and specific total discharge $q$ total

almost $1: 1$ between SS concentration and discharge except for a short period of time. It can be inferred that the August and October events were different in terms of discharge scale but similar in their sediment transport patterns.

Suspended sediment transport at Nukibetsu, as presented in Fig. 5, shows different patterns. The plotted hysteresis patterns for March and October are very similar. From a comparison of suspended sediment transport in a similar discharge range between Nukibetsu and Tomiuchi, it can be seen that SS concentration at Nukibetsu was several times higher than that at Tomiuchi.

In the August event, SS concentration showed several peaks, suggesting that additional sediment was supplied repeatedly due to collapses or other influences. This phenomenon cannot be discussed simply in terms of loop direction. It is necessary to observe the on-site sediment supply process in detail using video cameras and other methods [Fujita, 2003] in future studies to clarify the phenomenon. As it appeared that this type of sediment supply did not occur at Tomiuchi during the same event, the Saru river basin is considered to be characterized by conditions in which sediment is readily supplied.

Fig. 6 shows the total discharge and total SS load divided by the basin area. From the figure, it can be seen that sediment discharge was markedly different between these two observation points, regardless of the fact that variations in the data for
Tomiuchi were larger. The figure also indicates that sediment discharge was greater for the Saru river basin - a trend backed by the fact that additional sediment was supplied several times in the basin, as suggested by the hysteresis. This is considered to be a result of the Saru river basin being geologically susceptible to surface erosion during periods of heavy rainfall and the fact that collapses occurring during the heavy rains of 2003 produced easily transportable soil in the vicinity of the river channels, as reported by Murakami et al. [2008].

\subsection{Seasonal changes in sediment discharge patterns}

Fig. 7 shows mean SSC values plotted in chronological order for each event to allow examination of the trend of year-round changes in sediment discharge. It can be seen that the values for four basins (Nakajima was excluded because too many data were missing) have clear seasonal changes in common. The five observation points tended to have large mean SS concentration values in the snowmelt and summer seasons, and low values were seen between these two seasons from late May to June. The high SS concentration values observed for the snowmelt and summer seasons are considered to stem from the influence of high discharge in these seasons, which was easily affected by sediment supply associated with high discharge (i.e., stirred-up sediment from flood channels, etc.) and suspended sediment transported from eroded mountain slopes.

The low SS concentration values seen from May to June are believed to have been caused by low discharge along with the growth of vegetation, which hinders the supply of suspended sediment from slopes, and by the development of algae as a bed material in the river channel, creating an environment in which riverbed sediment is not readily stirred up by flowing water [Lawler et al., 2006]. The decrease in SS concentration seen after October is attributable to reduced precipitation, which resulted in low discharge and a corresponding

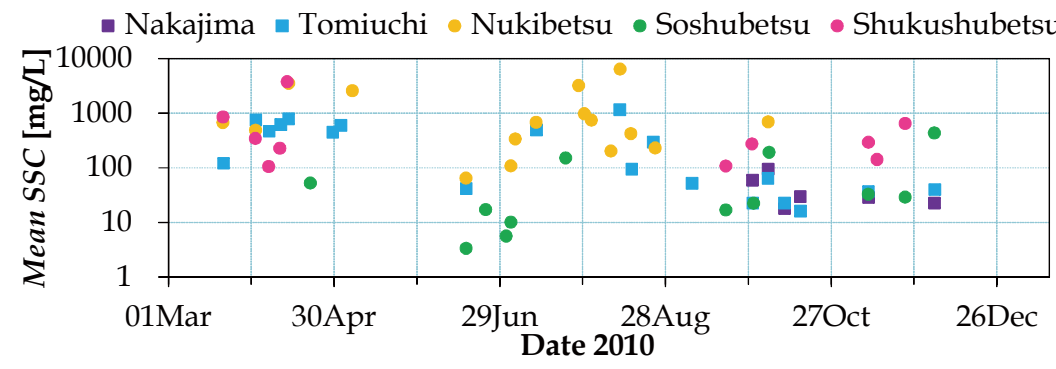

Fig.7 Seasonality effects on sediment delivery rates: Mean SSC per event throughout the season for 5 subcatchments. 
reduction in sediment supply to the river channels.

Based on the above, it was judged that sediment discharge patterns in the two basins could be divided into three periods of snowmelt, summer and other seasons, and the relationships between SS concentration and $Q$ in all events were plotted on $\log -\log$ axes for each season (Fig. 8).

For the Tomiuchi data shown in Fig. 8 (a), variations in SS concentration tended to be greater in the low discharge range. As outlined above, the plotted data for the latter half of events formed certain curves, so a clear lower limit for the relationship between SS concentration and $Q$ was found in the year-round monitoring. As indicated by Duvert et al. [2010], this lower limit corresponds to the minimum SS load that allows flowing water to erode riverbeds and transport sediment.

A line marking the upper limit of the plotted areas is seen in the top part of the plotted graph for summer flood events. This line is considered to represent the upper limit of channel sediment transport capacity. Under this condition, any amount of sediment exceeding the channel transport capacity will be deposited on the riverbed [Jansson, 2002]. Matter deposited in this way may be transported later when discharge changes. The upper limit for the snowmelt season (the green dotted line) does not reach the upper limit of the channel sediment transport capacity in the low discharge range, but does reach it as discharge increases. Accordingly, it can be inferred that sediment supply occurs even in the snowmelt season if the discharge becomes as large as that seen in the summer event.

Also at Nukibetsu, the upper and lower limits for the plotted data were observed as shown in Fig. 8 (b). However, the characteristics of these limits differ significantly from those for Tomiuchi. Due to the limited number of events extracted, it cannot be said for sure that the plotted data for SS concentration and $Q$ have a ratio of almost $1: 1$ regardless of the season for discharge of approximately $10 \mathrm{~m}^{3} / \mathrm{s}$ or less. From this, it can be inferred that the stirring up of riverbed sediment and sediment supply from slopes do not have an effect as long as the discharge remains below a certain level. This trend continues until discharge reaches about $40 \mathrm{~m}^{3} / \mathrm{s}$ for the events in the other seasons, but not in the snowmelt and summer seasons. The plotted data for summer flood events remain wholly within the range of those for snowmelt season flood events. Some SS concentration values for the summer season are tens of times higher than those for the snowmelt even for the same discharge.

In summary, the classification of hysteresis helped to clarify the characteristics of sediment discharge at each observation point in two basins. It is also possible to estimate to some extent the

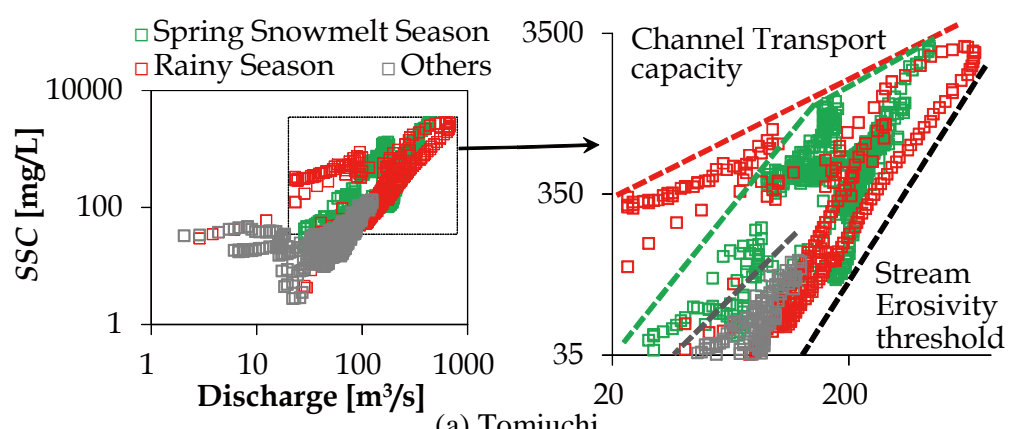

(a) Tomiuchi

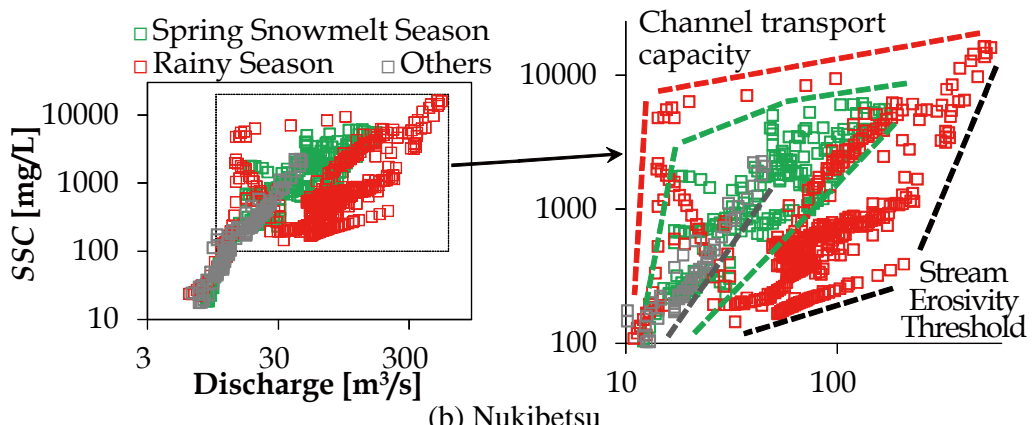

Fig.8 Seasonality effects on $S S C$ - $Q$ values obtained from event data collected all throughout the 2010. Green squares correspond to $S S C-Q$ data collected during spring snowmelt season (from March 21 to May 2), red ones correspond to events during rainy season (from July 12 to August 23), and grey correspond to all remaining event data (June 16 and period of September 6 to December 3). 
sources and causes of sediment movement using previously established techniques [Williams, 1989: Kurashige, 1996].

Subsequently, seasonal changes in the mean SS concentration for each event were examined. The results obtained throughout the year at the five observation points were comparable in terms of trend, but their absolute values varied, and sediment concentration (or sediment discharge) greatly differed between the $\mathrm{Mu}$ and Saru rivers. Plotted year-round $S S C-Q$ data for the snowmelt, summer and other seasons revealed that sediment transport characteristics differ between the basins.

At Tomiuchi on the Mu River, there was a lower limit boundary that represented the minimum erosive power, and there was also an apparent upper limit boundary for channel sediment transport capacity regardless of the season. In contrast, at Nukibetsu on the Saru River, the $S S C$ - $Q$ relationship was simple for small discharge events, but plotted data greatly varied with increased discharge. It can be inferred that sediment supply processes different from those in the Mu River frequently operated and became dominant in the Saru River.

\section{CONCLUSIONS}

In this study, two basins with turbid water located in the southern part of Hokkaido were continuously monitored over a period of a year using high-range turbidimeters. The results of the monitoring, which started in 2010, were used to successfully identify distinct seasonal changes in sediment discharge characteristics despite a significant number of missing data.

As a first step, turbidimeters were calibrated based on surface water sampling and analysis to allow estimation of SS concentration from turbidity measurements. The SS/Tb ratio was chosen as a convenient indicator of variations in particle size distribution. Since a high correlation was found between this ratio and discharge at the water sampling points, a simple equation for the estimation of SS concentration from discharge and turbidity measurements was proposed. Hydrological investigation also highlighted a good correlation between the indicator of variations in particle size and discharge. Accordingly, it can be said that the simple estimation equation has a certain level of validity.

The authors have not yet theoretically explained the linear correlation between channel discharge calculated from stage-discharge curves and the $S S / T b$ ratio as an indicator of particle size variations, so further studies are needed in this area. Case studies involving surface water sampling and turbidity monitoring in the basins need to be accumulated, and turbidimeter calibration must be conducted in laboratory experiments to further clarify the characteristics of these instruments.

Subsequently, the characteristics of sediment discharged from the basins and related seasonal changes were studied based on SSC- $Q$ hysteresis. The results showed that sediment discharge characteristics varied greatly between the basins, and that the differences in these characteristics stemmed from the basin area upstream of the points of turbidimeter installation. The hysteresis trend differed greatly even for the same event between Tomiuchi and Nukibetsu, indicating that the characteristics of sediment produced in the basins resulted from different causes.

It is necessary to continue turbidity monitoring as performed in this study, to accumulate data on rainfall, sediment discharge and transport processes, and to conduct a statistical study for each basin in order to clarify the characteristics of sediment production and discharge in them. Along with such efforts to improve the accuracy of the method for clarifying the nature of sediment discharge, the use of the tracer approach [Mizugaki et al., 2010] to predict sources of suspended sediment will help to elucidate sediment discharge from individual production sources. Information on suspended sediment dynamics in basins acquired from such studies is expected to contribute to the proposal of a more advanced and rational sediment management plan in the future.

ACKNOWLEDGMENT: The authors would like to express their gratitude to the Muroran Development and Construction Department at the Hokkaido Regional Development Bureau of the Ministry of Land, Infrastructure, Transport and Tourism for its support in providing precipitation and hydrological data, and to Fukuda Hydrologic Center Co., Ltd. and Hokkaisuiko Consultant Corporation for their support in the field surveys conducted.

\section{REFERENCES}

Ahn, Y., Nakamura, F. and Mizugaki, S. (2008): Hydrology, suspended sediment dynamics and nutrient loading in Lake Takkobu, a degrading lake ecosystem in Kushiro Mire, northern Japan, Environmental Monitoring and Assessment, No.145, pp. 267-281.

Bisantino, T., Gentile, F. and Liuzzi, G. T. (2011): Continuous monitoring of suspended sediment load in semi-arid environments, Sediment Transport, Chapter 15, InTech, pp. 295-312. 
Chappell, N., Douglas, I., Hanapi, J. and Tych, W. (2004): Sources of suspended sediment within a tropical catchment recovering from selective logging, Hydrological Processes, No.18, pp. 685-701.

Dietrich, W. (1982): Settling velocity of natural particles, Water Resources research, Vol. 18, No. 6, pp. 1615-1626.

Duvert, C., Gratiot, N., Evrard, O., Navratil, O., Nemery, J., Prat, C. and Esteves, M. (2010): Drivers of erosion and suspended sediment transport in three headwater catchments of the Mexican Central Highlands, Geomorphology, No.123, pp. 243-256.

Fujita, M., Sawada, T. and Mizuyama, T. (2003): Changes in turbidity and sediment movement in a small mountainous watershed, Annual Journal of Hydraulic Engineering, No.47, pp. 739-744 (in Japanese with English abstract).

Jansson, M. (2002): Determining sediment source areas in a tropical river basin, Costa Rica, Catena, No.47, pp. 63-84.

Kurashige, Y. (1985): Model for pulling up fine particles from armour-coated gravel bed in the early snowmelt season, Transactions, Japanese Geomorphological Union, No. 6, pp. 287-302.

Kurashige, Y. (1994): Mechanism of suspended sediment supply to headwater rivers, Transactions, Japanese Geomorphological Union, No. 15 (A), pp. 109-129.

Kurashige, Y. (1996): Recent studies on suspended sediment in river, Geophysical Bulletin of Hokkaido University, No.59, pp. 1-13 (in Japanese with English abstract).

Lawler, D., Petts, G., Foster, I. and Harper, S. (2006): Turbidity dynamics during spring storm events in an urban headwater river system: The Upper Tame, West Midlands, UK, Science of the Total Environment, No. 360, pp. 109-126.

Lewis, J. (1996): Turbidity-controlled suspended sediment sampling for runoff-event load estimation, Water Resources Research, No.32, pp. 2299-2310.

Mano, V., Nemery, J., Belleudy, P. and Poirel, A. (2009): Assessment of suspended sediment transport in four alpine watersheds (France): influence of the climatic regime, Hydrological Processes, No.23, pp. 777-792.

Mizugaki, S., Murakami, Y., Ohtsuka, J. and Uchida, T. (2010): Observation networks for suspended sediment dynamics in Mukawa River and Sarugawa River, Hokkaido, northern
Japan, Journal of the Japan Society of Erosion Control Engineering, Vol. 63, No.3, pp. 60-64 (in Japanese).

Murakami, Y., Shimizu, O., Sato, H. and Yamada, T. (2008): Sediment-related disaster caused by Typhoon 0310 (Etau) in Hidaka Region of Hokkaido, Japan, International Journal of Erosion Control Engineering, No.1, pp. 30-37.

Sumi, T., Baiyinbaoligao and Morita, S. (2006): Characteristics of fine sediment discharge during sediment flushing of Unazuki dam, Anuual Journal of Hydraulic Engineering, No.50, pp. 913-918 (in Japanese with English abstract).

Toyabe, T., Yamashita, S., Kizawa, K. and Hasegawa, K. (1998): The results of field measurement and analysis on September 1997 flood of the Mu River, Annual Journal of JSCE Hokkaido-branch, No.54, pp. 145-150 (in Japanese).

Wass, P. and Leeks, G. (1999): Suspended sediment fluxes in the Humber catchment, UK, Hydrological Processes, No.13, pp. 935-953.

Williams, G. P. (1989): Sediment concentration versus water discharge during single hydrologic events in rivers, Journal of Hydrology, No.111, pp. 89-106.

Yokoyama, H., Kizawa, K. and Hasegawa, K. (2000): On relation between water level change and hydraulic parameters during flood event of the Mu River, Proceedings of the 55th JSCE annual meeting, pp. 204-205 (in Japanese).

Yokoyama, K. (2002): The influence of particle size on turbidity output and the instructions for using turbidity sensor in the field, Annual Journal of Japan Society of Civil Engineering, No. 698, II-58, pp. 93-98 (in Japanese).

Yokoyama, K. (2005): Influence of sediment transport in the Chikugogawa and Shirakawa rivers on the coastal area of Ariake Bay, Ecology and Civil Engineering, No.8, pp. 61-72 (in Japanese with English abstract).

Yokoyama, K., Fujizuka, S., Nakazawa, T. and Takashima, S. (2008): Sediment yield and suspended sediment transport in the Chikugogawa River basin, Annual Journal of Hydraulic Engineering, No.52, pp. 553-558 (in Japanese with English abstract).

Yoshikawa, Y. and Watanabe, Y. (2005): Changes of the material transport depending on the flood scale, Proceedings of the 4th IAHR Symposium on River, Coastal and Estuarine Morphodynamics, pp. 319-328. 